\title{
BioMine: A database for metazoan biomineralization proteins
}

Biomineralization is the process by which living organisms construct hard skeletons creating complex structures that range from specialized tissues such as bone or teeth to ecosystems such as coral reefs. Biominerals are composed of both inorganic minerals and proteins, which give them extra hardness and special attributes. Biomineralization proteins are also known to be associated with multiple bone disorders and are therefore of biomedical importance. Herein we describe BioMine, a biomineralization centric protein database. Availability and implementation: BioMine can be accessed at http://biomine.net, SQL dump, FASTA files and source code are available for download as well. 
1 Authors: Bishoy S Kamel, Christian Voolstra ${ }^{2}$ and Mónica Medina ${ }^{1}$

2 Affiliations: ${ }^{1}$ Department of Biology, Pennsylvania State University, University Park,

3 PA, USA

$4 \quad{ }^{2}$ Red Sea Research Center, King Abdullah University of Science and Technology

5 (KAUST), Thuwal, Saudi Arabia

6

7 


\section{Introduction}

10 Biomineralization is a process in which minerals form inside or outside the cells of a

11 variety of organisms (Lowenstam \& Weiner 1989; Simkiss \& Wilbur 1989). In animals,

12 these minerals are primarily calcium carbonates and calcium phosphates (Knoll 2003).

13 The majority of biominerals formed in bones, shells, skeletons and spicules are composed

14 of mineral crystals, however all biominerals contain various amounts of other proteins

15 that give these minerals extraordinary properties. The cell orchestrates the mineral

16 formation process through the expression and translocation of proteins that nucleate the

17 crystals either intracellularly or extracellularly. More importantly, the cell has to inhibit

18 mineral formation and crystal growth in unwanted sites (Kawasaki et al. 2009; Marin et

19 al. 1996). Both nucleation and inhibition can be achieved through multiple cellular

20 mechanisms. For example, the cell will produce enzymes that modify proteins by

21 breaking them into smaller peptides (Qin et al. 2004) thus changing their function. The

22 cell is able to tightly regulate the biomineralization process by molecular modification

23 (e.g. adding sugars or other moieties) and regulation of ion transport across membranes

24 (Qin et al. 2004; Saavedra 1994; Sarashina et al. 2006). Such modifications to

25 biomineralization-associated proteins will determine how they interact with other

26 proteins, other cells, and with the biomineral in general. Biominerals are essential to the

27 survival of a broad range of animal taxa because they deliver protection against

28 predation, act as energy storage, provide support and unique optical properties (Addadi et

29 al. 2006). In particular, biomineralization plays a pivotal role in multiple human diseases

30 and other pathological phenomena such as coronary artery calcification (Atlan et al.

31 1997; Collette et al. 2010; Fisher et al. 2001; Lopez et al. 1992; Rousselle \& Heymann

32 2002; Salih et al. 1996; Wallin et al. 2001; Westbroek \& Marin 1998; Yang et al. 2002).

33 A growing interest in bio-inspired materials has generated a large body of work that uses

34 proteins and other biological scaffolds for in vitro mineralization and synthetic materials

35 (Chiu et al. 2012; Perry et al. 2009).

37 The process of biomineralization is ubiquitous throughout the animal tree. Such

38 distribution has generated speculation about the origin of metazoan biomineralization and 
39 its evolutionary history. Biomineralization is a complex process that relies on multiple

40 cellular pathways (Knoll 2003; Marin et al. 1996). Many of the studied biomineralization

41 proteins are part of other important processes such as cell adhesion, extracellular matrix

42 organization and immune functions (Bryden et al. 1999; Clendenon et al. 2009). This

43 evidence favors the idea that biomineralization independently evolved in multiple phyla

44 using pre-existing pathways in the early eumetazoan ancestor. It can also be argued that

45 biomineralization was present in the early eumetazoan ancestor yet various parts of the

46 pathway were lost in several animal lineages. According to fossil evidence and when

47 mapped onto a phylogeny, carbonate skeletons seem to have evolved at least 20 different

48 times in metazoans (Knoll 2003). If biomineralization evolved multiple times, it is

49 relevant to understand which components of the process exactly underwent innovations.

50 Since biomineralization is an active process, it requires 1) targeted localization of

51 calcium and carbonate, 2) an organic matrix as a template for the mineral nucleation, 3)

52 growth, and 3) efficient inhibitors in order to stop undesired calcification or even

53 formation of the mineral (Jackson et al. 2010; Marin et al. 1996). When all these different

54 requirements are taken into account, it seems unlikely that such diverse biochemical

55 processes involved in metazoan biomineralization evolved independently more than 20

56 times. A process such as transport is quite conserved across animal lineages and it shows

57 a clear history of gene duplication events (Dean et al. 2001; Saier et al. 2009). Such

58 complexity presents us with a conundrum. While the biomineralization process, with

59 different minerals and methods of calcification and clear evolutionary novelties, is found

60 across multiple animal phyla (Jackson et al. 2007a; Jackson et al. 2006; Jackson et al.

61 2009; Jackson et al. 2007b; Marin et al. 2000; Marin \& Luquet 2004; Marin et al. 2008;

62 Marin et al. 1996), it also remains that many parts of biomineralization pathways must be

63 conserved.

64

65 As a first step in tackling such questions in the evolution of animal biomineralization, we 66 have created a database to accumulate, annotate and curate biomineralization proteins and 67 protein-coding sequences. The database aims to serve the community by bridging the gap 68 between the few identified biomineralization proteins, and the unannotated plethora of 69 Expressed Sequence Tags (ESTs), draft genome gene models and next-generation 
70 sequencing datasets. We employed various bioinformatics techniques using domain-

71 based searches to collect and identify novel biomineralization proteins in metazoans. We

72 hope that due to the increasing surge of sequence information along with broad

73 phylogenetic representation in the public domain, a clearer picture of the evolutionary

74 history of biomineralization proteins will emerge, rendering BioMine as a dynamic

75 platform to answer not only fundamental questions in animal evolution but also about the

76 process of biomineralization in particular lineages.

78 Methods

\section{Biomineralization proteins list}

80 We carried out a wide primary literature and database survey in order to compile a list of

81 proteins that are functionally implicated biomineralization in animals. Specifically, we

82 included data from scleractinian corals, calcareous sponges, gastropod and bivalve

83 molluscs, crustaceans, echinoderms, and vertebrates. Additional sequences were collected

84 from the AMIGO Gene Ontology database (Carbon et al. 2009). The complete

85 biomineralization gene list is accessible through the BioMine web application

86 (http://biomine.net/). These already annotated sequences were used as a seed to search for

87 related biomineralization proteins in undocumented taxa or new sequence databases, and

88 were stored in a pre-computed BLAST search database. After building the list of

89 candidate proteins, each protein could be traced back to an original publication where it

90 was described.

91

92 Pfam domain search and protein homolog identification

93 To further improve the search strategy, using the Pfam database, we scanned for

94 conserved protein domains in the proteins we gathered from primary literature (Finn et al.

95 2008). The identified domains in the already known biomineralization proteins were

96 scanned against 6-frame translations of ESTs and protein sequences from dbEST and nr

97 databases (NCBI) of the taxa Cnidaria, Mollusca, Echinodermata and Vertebrata using

98 the HMMER 3 package (Eddy 2008; Eddy 2011). The tool used for the translation was

99 sixpack from the EMBOSS package (Rice et al. 2000).

100 
102 In addition to the domain searches, we conducted BLASTp searches for all the proteins in

103 the seed database against $\mathrm{nr}$ and against the 6-frame translations of the dbEST for the

104 selected taxa. For filtering the results, we only considered hits that match e-value $>$

1050.000001 and bitscore $>150$ to be significant.

\section{BioMine construction}

108 In order, to organize all the data in a searchable platform, we constructed a web application that enables us to search the results and to submit new sequences into the

110 database. BioMine is written in PHP and Perl, and relies on MySQL for relational

111 information Source code for BioMine is under GPL v3 at

112 http://code.google.com/p/biomine/. The MySQL database contains the results of all the

113 HMMER results in addition to the BLAST results and FASTA files of all sequences can

114 be downloaded from the website.

\section{Results}

117 After assembling the initial list of biomineralization-related proteins, we identified

118 putative homologs of given candidate genes in calcifying lineages (molluscs, cnidarians,

119 arthropods and echinoderms). A protein domain search was initiated on our candidate list

120 of 472 proteins, based on Pfam models using HMMER 3 (Eddy 2008). In the Pfam

121 search 198 domain families were found to be linked to biomineralization. The search

122 results were stored in a relational database linking the detected domains with the species

123 in addition to detected orthologs for every particular protein.

124 Below we describe two potential scenarios for the use of BioMine by the scientific

125 community.

126 Use case 1:

127 1) A user prepares a list of proteins from a newly sequenced organism.

2) The user submits the protein list to BioMine through the web interface.

3) BioMine generates potential matching biomineralization proteins in the submitted dataset, together with the publications in which these similar proteins have been described. In addition, a predicted protein-protein interaction network will be generated if the submitted protein list can be decomposed successfully to Pfam domains. These domains are obtained from the Pfam database, which contains curated conserved domains of various functions 
Use case 2:

\section{Discussion and Conclusion}

146 By combining thorough literature scrutiny with similarity searches we were able to

147 construct a large dataset of biomineralization-related proteins. BioMine proved useful in

148 annotating sequence data from non-model organisms involved in the particular process of 149 biomineralization. The ability to always link back to the primary literature provides a 150 unique opportunity to the investigator to directly examine the experimental evidence that 151 deemed a particular protein as biomineralization-associated. We believe this should fast-

152 forward research in non-model systems by knowledge transfer from model species in

153 biomineralization research. By providing a BLAST interface and downloadable versions,

154 we are certain that biomineralization researchers can benefit from BioMine. BioMine is a

155 dedicated database containing manually curated biomineralization proteins from all

156 mineralizing animal taxa that is presented through a user-friendly fully searchable

157 interface. 


\section{References}

Addadi L, Joester D, Nudelman F, and Weiner S. 2006. Mollusk Shell Formation: a

$$
\text { Chemistry - A European Journal 12:980 - } 987
$$

Atlan G, Balmain N, Berland S, Vidal B, and Lopez É. 1997. Reconstruction of human maxillary defects with nacre powder: histological evidence for bone regeneration. Comptes Rendus de l'Académie des Sciences - Series III - Sciences de la Vie 320:253-258.

Bryden AA, Freemont AJ, Clarke NW, and George NJ. 1999. Paradoxical expression of E-cadherin in prostatic bone metastases. BJU Int 84:1032-1034. bju378 [pii]

Carbon S, Ireland A, Mungall CJ, Shu S, Marshall B, and Lewis S. 2009. AmiGO: online access to ontology and annotation data. Bioinformatics 25:288-289. btn615 [pii]

10.1093/bioinformatics/btn615

Chiu D, Zhou W, Kitayaporn S, Schwartz DT, Murali-Krishna K, Kavanagh TJ, and Baneyx F. 2012. Biomineralization and size control of stable calcium phosphate core-protein shell nanoparticles: potential for vaccine applications. Bioconjug Chem 23:610-617. 10.1021/bc200654v

Clendenon SG, Shah B, Miller CA, Schmeisser G, Walter A, Gattone VH, 2nd, Barald KF, Liu Q, and Marrs JA. 2009. Cadherin-11 controls otolith assembly: evidence for extracellular cadherin activity. Dev Dyn 238:1909-1922. 10.1002/dvdy.22015

Collette NM, Genetos DC, Murugesh D, Harland RM, and Loots GG. 2010. Genetic evidence that SOST inhibits WNT signaling in the limb. Dev Biol 342:169-179. S0012-1606(10)00187-9 [pii]

10.1016/j.ydbio.2010.03.021

Dean M, Hamon Y, and Chimini G. 2001. The human ATP-binding cassette (ABC) transporter superfamily. J Lipid Res 42:1007-1017.

Eddy SR. 2008. A probabilistic model of local sequence alignment that simplifies statistical significance estimation. PLoS Comput Biol 4:e1000069. 10.1371/journal.pcbi.1000069

Eddy SR. 2011. Accelerated Profile HMM Searches. PLoS Comput Biol 7:e1002195. 10.1371/journal.pcbi.1002195

Finn RD, Tate J, Mistry J, Coggill PC, Sammut SJ, Hotz H-R, Ceric G, Forslund K, Eddy SR, Sonnhammer ELL, and Bateman A. 2008. The Pfam protein families database. Nucl Acids Res 36:D281-288. 10.1093/nar/gkm960

Fisher LW, Torchia DA, Fohr B, Young MF, and Fedarko NS. 2001. Flexible structures of SIBLING proteins, bone sialoprotein, and osteopontin. Biochem Biophys Res Commun 280:460-465. 10.1006/bbrc.2000.4146

S0006-291X(00)94146-9 [pii]

Jackson DJ, Macis L, Reitner J, Degnan BM, and Worheide G. 2007a. Sponge paleogenomics reveals an ancient role for carbonic anhydrase in skeletogenesis. Science 316:1893-1895. 1141560 [pii]

10.1126/science. 1141560

Jackson DJ, McDougall C, Green K, Simpson F, Worheide G, and Degnan BM. 2006. A rapidly evolving secretome builds and patterns a sea shell. BMC Biol 4:40. 
Jackson DJ, McDougall C, Woodcroft B, Moase P, Rose RA, Kube M, Reinhardt R, Rokhsar DS, Montagnani C, Joubert C, Piquemal D, and Degnan BM. 2009. Parallel evolution of nacre building gene sets in molluscs. Mol Biol Evol:msp278. 10.1093/molbev/msp278

Jackson DJ, Thiel V, and Worheide G. 2010. An evolutionary fast-track to biocalcification. Geobiology. GBI236 [pii]

10.1111/j.1472-4669.2010.00236.x

Jackson DJ, Worheide G, and Degnan BM. 2007b. Dynamic expression of ancient and novel molluscan shell genes during ecological transitions. BMC Evol Biol 7:160. $1471-2148-7-160$ [pii]

10.1186/1471-2148-7-160

Kawasaki K, Buchanan AV, and Weiss KM. 2009. Biomineralization in humans: making the hard choices in life. Annual review of genetics 43:119-142.

Knoll AH. 2003. Biomineralization and Evolutionary History. Reviews in Mineralogy and Geochemistry 54:329-356. 10.2113/0540329

Lopez E, Vidal B, Berland S, Camprasse S, Camprasse G, and Silve C. 1992. Demonstration of the capacity of nacre to induce bone formation by human osteoblasts maintained in vitro. Tissue and Cell 24:667-679.

Lowenstam HA, and Weiner S. 1989. On Biomineralization. New York: Oxford University Press.

Marin F, Corstjens P, de Gaulejac B, de Vrind-De Jong E, and Westbroek P. 2000. Mucins and Molluscan Calcification. MOLECULAR CHARACTERIZATION OF MUCOPERLIN, A NOVEL MUCIN-LIKE PROTEIN FROM THE NACREOUS SHELL LAYER OF THE FAN MUSSEL PINNA NOBILIS (BIVALVIA, PTERIOMORPHIA). J Biol Chem 275:20667-20675. 10.1074/jbc.M003006200

Marin F, and Luquet G. 2004. Molluscan Shell Proteins. Comptes Rendus Palevol 3:469492.

Marin F, Luquet G, Marie B, and Medakovic D. 2008. Molluscan shell proteins: primary structure, origin, and evolution. Curr Top Dev Biol 80:209-276. S00702153(07)80006-8 [pii]

10.1016/S0070-2153(07)80006-8

Marin F, Smith M, Isa Y, Muyzer G, and Westbroek P. 1996. Skeletal matrices, muci, and the origin of invertebrate calcification. Proc Natl Acad Sci U S A 93:15541559.

Perry CC, Patwardhan SV, and Deschaume O. 2009. From biominerals to biomaterials: the role of biomolecule-mineral interactions. Biochem Soc Trans 37:687-691. 10.1042/BST0370687

Qin C, Baba O, and Butler WT. 2004. POST-TRANSLATIONAL MODIFICATIONS OF SIBLING PROTEINS AND THEIR ROLES IN OSTEOGENESIS AND DENTINOGENESIS. Critical Reviews in Oral Biology \& Medicine 15:126-136.

Rice P, Longden I, and Bleasby A. 2000. EMBOSS: the European molecular biology open software suite. Trends in genetics 16:276-277.

Rousselle AV, and Heymann D. 2002. Osteoclastic acidification pathways during bone resorption. Bone 30:533-540. S8756328202006725 [pii] 
Saavedra RA. 1994. The roles of autophosphorylation and phosphorylation in the life of osteopontin. BioEssays 16:913-918. 10.1002/bies.950161210 Classification Database: recent advances. Nucleic Acids Res 37:D274-278. 10.1093/nar/gkn862

Salih E, Ashkar S, Gerstenfeld LC, and Glimcher MJ. 1996. Protein kinases of cultured osteoblasts: selectivity for the extracellular matrix proteins of bone and their catalytic competence for osteopontin. J Bone Miner Res 11:1461-1473. $10.1002 / \mathrm{jbmr} .5650111013$

Sarashina I, Yamaguchi H, Haga T, Iijima M, Chiba S, and Endo K. 2006. Molecular Evolution and Functionally Important Structures of Molluscan Dermatopontin: Implications for the Origins of Molluscan Shell Matrix Proteins. Journal of Molecular Evolution 62:307-318. 10.1007/s00239-005-0095-2

Simkiss K, and Wilbur KM. 1989. Biomineralization. Cell Biology and Mineral Deposition. San Diego, CA: Academic Press.

Wallin R, Wajih N, Greenwood GT, and Sane DC. 2001. Arterial calcification: a review of mechanisms, animal models, and the prospects for therapy. Med Res Rev 21:274-301.

Westbroek P, and Marin F. 1998. A marriage of bone and nacre. Nature 392:861-862. $10.1038 / 31798$

Yang RS, Tang CH, Ling QD, Liu SH, and Fu WM. 2002. Regulation of fibronectin fibrillogenesis by protein kinases in cultured rat osteoblasts. Mol Pharmacol 61:1163-1173. 